\title{
Considerações teóricas aligeiradas sobre a catalogação e sua aplicação
}

\author{
Brief theoretical considerations about cataloging and its application
}

\author{
Eliane Serrão Alves Mey \\ Doutora em Ciência da Informação pela ECA/USP. \\ Pesquisadora visitante, Escola de Biblioteconomia/UNIRIO, Bolsista FAPERJ \\ Docente aposentada, UFSCar \\ E-mail: elimey@ufscar.br \\ Naira Christofoletti Silveira \\ Docente, Escola de Biblioteconomia/UNIRIO \\ Doutoranda em Ciência da Informação, Escola de Comunicação e Artes/USP \\ E-mail: naira_csilveira@yahoo.com.br
}

\section{Resumo}

Reflete sobre os conceitos teóricos que permeiam a catalogação e a prática irreflexiva de alguns instrumentos biblioteconômicos. Inicialmente aborda a prática da catalogação, com exemplos sobre uso da CDD e das AACR2. Argumentam e explicam o emprego mecânico desses instrumentos. Por fim, recorre a conceitos de Adorno e apropria-se das pretensões de validade de Habermas para reafirmar o papel da comunicação na representação bibliográfica e a importância da análise crítica e reflexiva desta área.

Palavras-chave: Catalogação. Representação bibliográfica. Registro bibliográfico. Ação comunicativa.

\begin{abstract}
It consists of a reflexive thinking about theoretical concepts on cataloguing and the thoughtless practice of cataloguing tools. Initially, it approaches cataloguing practice, through DDC and AACR2 examples, as applied in Brazil. It explains the mechanical uses of those tools. At last, it turns to Adornian concepts and takes the Habermas' validity intentions to reafirm the role of communication for bibliographic representation, and the importance of critical and reflexive analysis for this area.
\end{abstract}

Keywords: Cataloguing. Bibliographic record. Communicative action.

\section{Introdução}

Muito hoje se discute sobre a aplicação da catalogação, aqui considerada em sentido amplo, abrangendo tanto a catalogação, ou representação bibliográfica, seja esta descritiva, ou representação descritiva, e a catalogação dita de assuntos, ou representação temática. Não se nega, em momento algum, a amplitude e profundidade dessas diferentes facetas da mesma catalogação; porém, é preciso visualizá-las como um todo, uma vez que se elabora um único registro bibliográfico.

InCID: R. Ci. Inf. e Doc., Ribeirão Preto, v. 1, n.1, p. 125-137, 2010. 
Primeiramente, cabe explicitar a definição e o sentido da representação bibliográfica. Entendemos a catalogação como o estudo, a preparação e a organização de mensagens, com base em registros do conhecimento, reais ou ciberespaciais, existentes ou passíveis de inclusão em um ou vários acervos, visando a criar conteúdos comunicativos que permitam a interseção entre as mensagens contidas nestes registros do conhecimento e as mensagens internas dos usuários.

Há vários conceitos para o termo representação, tanto oriundos de diferentes linhas filosóficas como de diferentes áreas do conhecimento: da Arte ao Direito, ou seja, da criação à regulamentação. $\mathrm{O}$ sentido intencional da catalografia refere-se à representação como 'algo no lugar de'.

Os registros bibliográficos, produtos da catalogação que constituem um catálogo, ou base de dados, entre outros possíveis, normatizam-se por meio de padrões internacionalmente acordados, como a International Standard Bibliographic Description - ISBD (IFLA, 2007) e os Princípios de Catalogação de 2009. (DECLARAÇÃO..., 2009) Cabe ressaltar que as normas para metadados, embora aparentemente não se assemelhem à ISBD, têm com esta total compatibilidade quanto à transcrição de elementos. A diferença repousa na pontuação, (diga-se, corretamente) considerada dispensável para certos ambientes eletrônicos. Tal posição reafirma-se no código Resource Descripton and Access - RDA, (RDA..., 2009) ou Descrição e Acesso ao Recurso, editado em 2010 como substituto às Anglo-American Cataloguing Rules $2^{\text {nd }}$ edition (AACR2). O RDA não apresenta as pontuações estabelecidas como precedentes e sucedentes a cada área da descrição bibliográfica, como prescritas na ISBD.

\section{Códigos de catalogação e os principios internacionais}

A Declaração dos Princípios Internacionais de Catalogação (DECLARAÇÃO..., 2009, p. 3-4), substituta dos Princípios de Paris (DECLARACIÓN..., 1961), determina, como fundamento para a construção de códigos de catalogação, a conveniência do usuário. Determina, também:

O catálogo deve ser um instrumento efetivo e eficiente que permita ao usuário:

4.1 Encontrar recursos bibliográficos em uma coleção como o resultado de uma busca, usando atributos e relações entre recursos:

4.1.1 localizar determinado recurso

4.1.2 localizar conjuntos de recursos representando

InCID: R. Ci. Inf. e Doc., Ribeirão Preto, v. 1, n.1, p. 125-137, 2010. 
todos os recursos que pertencem a uma mesma obra todos os recursos que incorporam uma mesma expressão todos os recursos que exemplificam uma mesma manifestação

todas os recursos associados a determinada pessoa, família, ou entidade coletiva todos os recursos sobre determinado assunto

todos os recursos definidos por outros critérios (língua, país de publicação, data de publicação, tipo de conteúdo, tipo de suporte etc.) geralmente como filtro secundário de busca;

4.2 identificar um recurso bibliográfico ou agente (isto é, confirmar que a entidade descrita corresponde à entidade desejada ou distinguir entre duas ou mais entidades com características similares);

4.3 selecionar um recurso bibliográfico apropriado ao usuário (isto é, escolher um recurso que esteja de acordo com as necessidades do usuário no que diz respeito ao meio, conteúdo, suporte etc. ou rejeitar um recurso não apropriado às necessidades do usuário);

4.4 adquirir ou obter acesso a um item descrito (isto é, fornecer informação que capacite o usuário a adquirir um item por meio de compra, empréstimo etc., ou acessar um item eletronicamente por meio de conexão on-line a uma fonte remota); ou acessar, adquirir ou obter um dado de autoridade ou bibliográfico.

4.5 navegar em um catálogo e além dele (isto é, por meio do arranjo lógico dos dados bibliográficos e de autoridade e de maneiras claras de se fazer esta navegação, incluindo a apresentação de relações entre obras, expressões, manifestações, itens, pessoas, famílias, entidades coletivas, conceitos, objetos, eventos e lugares).

Consequentemente, vê-se o catálogo, produto da catalogação, como meio comunicativo para interação entre criador, usuário e documento, em seu sentido amplo. Podese afirmar que o criador (autor, artista, ou qualquer outro responsável pelo conteúdo intelectual de uma obra) espera que o fruto de seu trabalho seja conhecido ou descoberto por um usuário. Por sua vez, o usuário espera encontrar aquele item de seu interesse (não apenas a obra, mas o item em si, acessível). O documento, seja ele obra, expressão, manifestação ou item, ver FRBR, (IFLA, 1998) espera ser encontrado por um usuário. Por fim, o profissional da documentação necessita encontrar documentos reais ou ciberespaciais já registrados bibliograficamente, para: a) levantar itens de interesse a seus próprios usuários; b) obter auxílio para o desenvolvimento de coleções; c) utilizar registros já elaborados, evitando duplicidade de esforços.

\section{Características da catalogação}

Ao visarmos a possibilidade de um usuário realizar as funções indicadas na Declaração, consideramos como características indispensáveis à catalogação: integridade, clareza, precisão, lógica e consistência. Esses atributos refletem-se, por sua vez, nos próprios catálogos e demais produtos da representação bibliográfica. Identificam-se aquelas características:

InCID: R. Ci. Inf. e Doc., Ribeirão Preto, v. 1, n.1, p. 125-137, 2010. 
- integridade significa fidelidade, honestidade na representação, transmitindo informações passíveis de verificação;

- clareza significa que a mensagem deve ser compreensível aos usuários;

- precisão significa que cada uma das informações só pode representar um único conceito, sem dubiedades ou dúvidas;

- lógica significa que as informações devem ser organizadas de modo lógico;

- consistência significa que a mesma solução deve ser sempre usada para informações semelhantes.

Tais características relacionam-se às funções maiores de compreensão dos produtos catalográficos por parte do usuário e de auxílio ao mesmo. Para atingir essas funções, a catalogação utiliza-se de linguagem catalográfica, que possui semântica e sintaxe próprias. Ademais, o ato de catalogar segundo regras internacionalmente acordadas pressupõe a hermenêutica da catalografia.

A sintaxe se constitui de posição e pontuação. Ou seja, cada elemento descritivo, ao registrar uma característica ou atributo de uma entidade (no sentido dos FRBR), possui uma posição determinada. Tal posição se encontra explícita no registro bibliográfico elaborado por meio da ISBD, ou em bases de dados catalográficas, segundo campos identificados em formatos para uso por meio eletrônico. A pontuação, estabelecida na primeira norma ISBD (1971) e mantida nas sucedâneas, indica o elemento bibliográfico que se lhe segue.

A semântica dá significado aos termos em sua posição e respectiva pontuação precedente.

A hermenêutica consiste na interpretação dos códigos e normas adotados, tanto nacional como internacionalmente, e se constitui no principal aspecto do trabalho de catalografia. O correto entendimento da regra, aliado à análise da entidade a se representar, consolidam a estrutura do catálogo ou base de dados documental e sua inter-relação com os usuários e demais instituições.

Aquelas características da catalogação, juntamente com suas gramática e hermenêutica, constituem os fundamentos do processo comunicativo, ou elaboração das mensagens da catalogação, tendo em vista seus usuários.

InCID: R. Ci. Inf. e Doc., Ribeirão Preto, v. 1, n.1, p. 125-137, 2010. 


\section{Quem seria o usuário?}

Quem seria o usuário, do qual muito falamos e tão pouco conhecemos (especialmente os catalogadores)? Em primeiro lugar, torna-se indispensável compreender que todos possuem múltiplas facetas. Hoje, em seu trabalho, este indivíduo precisa de determinado tipo de informação. O mesmo indivíduo, amanhã, necessita ou deseja outro tipo de informação, ao visar outros fins, como o lazer. Pode ser também o profissional documentalista, que necessita da informação para seu trabalho ou para seus próprios usuários, porque nenhuma instituição documental é uma ilha. Hoje usuário; amanhã criador; em outro momento, profissional da documentação; em outros espaços, parte de um grupo com interesses comuns: o usuário é, ao mesmo tempo, um e múltiplo. Em segundo lugar, todos os indivíduos pertencem a um determinado espaço sociocultural, com determinadas características próprias. A principal dentre elas centra-se na linguagem. Mesmo a música ou as artes plásticas, linguagens universais, explicam-se e compreendem-se por meio do conhecimento dos contextos em que se criaram tais obras. Há particularidades indicativas de suas origens.

Uma vez que a catalogação utiliza-se da linguagem, assim como de conceitos culturalmente estabelecidos (por exemplo: o conceito de autoria), precisa conhecer profundamente seus usuários e o grupo, comunidade ou sociedade no qual se inserem, de modo a empreender o processo comunicativo.

O processo comunicativo se dá em sociedades ou comunidades permeadas por linhas de pensamento e visões de mundo, que regem e direcionam suas práticas, suas condutas e sua busca e disseminação do conhecimento.

No caso específico da Biblioteconomia e da Ciência da Informação, Mostafa (1985) demonstrou serem ambas de mesma origem kantiana, ou neokantiana. Parece claro estar a Ciência da Informação estreitamente vinculada à teoria tradicional, por sua crença no distanciamento e na neutralidade do profissional, na objetividade dos estudos, na redução dos fenômenos observados a fórmulas matemáticas (Lei de Bradford, por exemplo, entre inúmeras outras). Acima de tudo, tem-se pautado pela busca de explicações teóricas gerais, de leis universais, dentro dos padrões vigentes do cientificismo asséptico. 
Mostafa (1985, p. 60) também apontou as características positivistas da

Biblioteconomia:

O credo bibliotecário de ser um guardião do conhecimento "sem política, sem religião, sem moral" é revelador da neutralidade científica (pressuposto absoluto do positivismo) implícito na própria organização do conhecimento, onde os conteúdos são dispostos linearmente, possuindo todos o mesmo valor, o mesmo grau de relevância e objetividade [...]; ao bibliotecário importa dispor os conteúdos (mesmo que ele passe de uma classificação aristotélica de Dewey para sistemas póscoordenados); dispondo positivisticamente esse conteúdo, o bibliotecário reza outro credo do ideário informacional: servir a instituição patronal à qual a biblioteca se subordina, por onde ela orienta todo o seu processo de seleção, compondo as coleções sempre sob rigorosa adequação aos objetivos da organização mantenedora (de todos os credos, a compatibilidade da política de aquisição com os objetivos organizacionais é de consenso absoluto).

Em suma, Mostafa identificou a teoria tradicional em todas as etapas da prática bibliotecária: seleção e aquisição, representação bibliográfica e disseminação. Esta última, embora não citada no parágrafo acima, se encontra implícita, tanto nos produtos da representação (catálogos, por exemplo), como à conta dos mecanismos oriundos da Ciência da Informação (estudos de uso e usuários, por exemplo). Por fim, Mostafa (1985, p. 3), apontou o "quadro de perfeita dicotomia entre teoria e prática." O que nos leva a um interregno com Adorno (1992, p. 74-5), em sua reflexão sobre o tema:

Deveria ser criada uma consciência de teoria e prática que não separasse ambas, deixando a teoria impotente e a prática arbitrária, e que não destruísse a teoria pelo primado da razão prática, como nos primeiros tempos da burguesia e como proclamado por Kant e Fichte. Pensar é uma forma de atuar e a teoria é uma forma de prática; só a ideologia da pureza do pensamento é que se engana a esse respeito.

Embora, na aparência, considerem-se tais limites impostos pela teoria tradicional ultrapassados, estes ainda refletem-se nas limitações de nossas práticas e teorias, impedindo que as instituições documentárias cumpram sua função transformadora.

\section{Exemplos curiosos no uso das regras de classificação e catalogação}

Exemplificam-se, a seguir, as afirmativas anteriores. 
Iniciamos os exemplos com excertos da Classificação Decimal de Dewey (CDD), $22^{\mathrm{a}}$ edição, introdução às divisões 810-890 - Literaturas de idiomas específicos e famílias de idiomas:

\footnotetext{
A Literatura é classificada pelo idioma no qual foi originalmente escrita

[...]

Os números usados nesta tabela para literaturas de idiomas individuais não necessariamente correspondem de modo exato àqueles em 420-490, ou à notação na Tabela 6. [...]

(Opção: para dar tratamento preferencial, ou tornar disponíveis mais números e [números] mais curtos para classificação de uma literatura, em qualquer idioma que se deseje enfatizar, utilize uma das seguintes opções:

Opção A: Classifique em 810, onde aparecem instruções completas [grifo nosso] Opção B: [...]

Opção C: [...] (DEWEY, 2003, v. 3, p. 773)
}

A mesma opção A reaparece sob a divisão 810 da CDD.

Pelo visto, a literatura mais importante para nós, brasileiros, que merece destaque total, é a americana (aqui se incluem, segundo a CDD, a América do Norte, América do Sul, o Havaí e outras ilhas adjacentes; pasme-se!), pois continuamos a classificar a literatura americana em 810, e não em 820, seu lugar adequado, junto às demais literaturas de língua inglesa e em equanimidade de significação para nós. Cabe relembrar que as opções propostas pela CDD permitem destaque à literatura mais significativa para determinada comunidade usuária, independentemente de sua localização geográfica. Se um acervo destina-se a um tipo específico de cultura, como a japonesa ou a árabe, por exemplo, mesmo que situada no Brasil, precisa iniciar sua organização física das classes 810-890 pela produção literária da cultura específica, pois que esta deve destacar-se no conjunto.

Veja-se agora um trecho do Código de Catalogação Anglo-Americano, $2^{\mathrm{a}}$ edição, tradução brasileira, 2002, Regra 24.18A:

\footnotetext{
Faça entrada subordinada para um órgão governamental sob o nome do governo, se ele pertencer a um ou a mais dos tipos seguintes. [...]

TIPO 1. Um órgão cujo nome contenha um termo que, por definição, indique ser a entidade parte de outra, (p.ex., Departamento, Divisão, Seção, Setor, e seus equivalentes em outras línguas) [grifo nosso].
}

Ou seja, a regra exige interpretação. Ninguém discute a necessidade de cabeçalho subordinado a uma instituição maior no caso de Departamento de Pessoal e assemelhados. No entanto, para os Estados Unidos, a palavra Departamento significa também Ministério, o que leva à subordinação por definição, do termo Department. O mesmo não se dá com os Departamentos Nacionais brasileiros, autarquias, com tanta subordinação como as InCID: R. Ci. Inf. e Doc., Ribeirão Preto, v. 1, n.1, p. 125-137, 2010. 
Superintendências, ou suas sucessoras, as atuais Agências. No entanto, a hermenêutica, explicitada no Documento da Biblioteca Nacional (porém, faça-se justiça: não interpretada apenas pela nossa $\mathrm{BN})$, preconiza:

1.1 Considerar para o Brasil como termos que por definição indicam que a entidade é parte de outra os seguintes: departamento, divisão seção, setor. [...]

Ex:

Brasil. Departamento Nacional de Obras contra as Secas.

Brasil. Ministério da Agricultura. Departamento de Pessoal.

Bahia. Departamento de Estradas de Rodagem. (BIBLIOTECA, 2003, p. 169)

Por outro lado, a regra 1.3 indica:

1.3 Fazer entrada direta para entidades cujos nomes não sejam únicos nos seguintes casos:

1.3.1 Entidade cujos nomes contêm os seguintes termos: agência, [...] superintendência [...].(BIBLIOTECA, 2003, p. 169-170)

Em conseqüência, o DNER, ou Departamento Nacional de Estradas de Rodagem, cujo nome aparecia nas placas de todas as estradas brasileiras, possuía a entrada:

Brasil. Departamento Nacional de Estradas de Rodagem.

Hoje, sua substituta, a Agência Nacional de Transportes Terrestres, ou ANTT, possui a entrada:

Agência Nacional de Transportes Terrestres (Brasil)

o que sempre preconizamos (nós e outros catalogadores, mais experientes) para o DNER.

Outros problemas apresentam-se, porém necessitados de estudos mais profundos e conjuntos com especialistas em representação temática; por exemplo: as entidades de assunto dos FRBR comparadas às categorias de Ranganathan, ao Precis e aos cabeçalhos de assunto da Library of Congress.

Valnir Chagas (1982) cita em sua obra o "complexo de Frankenstein”, referindo-se ao "uso da ciência sem sabedoria". Cabe aqui uma paráfrase do mesmo complexo de Frankenstein: o uso das técnicas sem sabedoria, que abarca desde as lacunas hermenêuticas até o endeusamento das tecnologias. Atenta-se, deste modo, para um problema, não apenas 
bibliotecário, mas profissional brasileiro: o emprego incondicional de técnicas e instrumentos, não exatamente adequados àqueles aos quais se destinam.

Portanto, precisamos voltar-nos aos princípios comunicativos (a despeito das limitações do trabalho, reconhece-se que não unicamente a esses). Antes de atingir o objetivo maior, ou seja, apontar a indispensável abordagem de base teórica significativa à catalogação, cabe um breve parêntese sobre a teoria tradicional na comunicação.

Mattelart e Mattelart (2003) relatam a origem do texto clássico de Shannon e Weaver sobre o processo comunicativo. Segundo aqueles autores, o engenheiro elétrico e matemático Claude E. Shannon, enquanto trabalhava para os laboratórios da Bell Systems (subsidiária da American Telegraph \& Telephone - AT\&T), desenvolveu monografia sobre uma teoria matemática da comunicação. Acrescido de comentários de Warren Weaver, o texto foi (re)publicado em 1949 e tornou-se ícone de um sistema geral de comunicação. Em vista de sua fama internacional e multidisciplinar, basta lembrar que Shannon iniciou o trabalho visando a "quantificar o custo de uma mensagem, de uma comunicação entre os dois polos desse sistema, em presença de perturbações aleatórias, denominadas 'ruídos', indesejáveis porque impedem o 'isomorfismo', a plena correspondência entre os dois polos" (MATTELART; MATTELART, 2003, p. 58-9).

Mesmo que se reconheça a obsolescência da teoria face às ciências humanas e sociais, clara está sua permanência junto às mesmas, por meio das tecnologias eletrônicas e ciberespaciais, com total desconhecimento dos interesses dos usuários; por exemplo: nos caixas eletrônicos bancários, nas dificuldades de acesso e obtenção de informações em sítios da internet, entre outros. Retorna-se, deste modo, às antigas questões, sempre atuais, colocadas por Adorno e Horkheimer (1985) quanto ao conceito de esclarecimento e à indústria cultural, que explicam a longa vida do positivismo, em suas inúmeras formas, vertentes e atualizações.

Deveríamos, talvez, os que trabalhamos com a representação bibliográfica, aprofundar-nos na obra-prima adorniana Dialética negativa (ADORNO, 1975), em que este autor trata do conceito, entre outros temas de nosso interesse. Todas as nossas representações baseiam-se em conceitos, vistas a semântica da catalogação como um todo e a semântica própria à representação de assuntos. Segue pequeno trecho de Adorno (1975, p. 20), do tópico Desmitologización del concepto, visando a demonstrar como necessitamos de outros pontos de vista nas nossas teorias da representação:

InCID: R. Ci. Inf. e Doc., Ribeirão Preto, v. 1, n.1, p. 125-137, 2010. 
La verdad es que todos los conceptos, incluidos los filosóficos, tienen su origen en lo que no es conceptual, ya que son a su vez parte de la realidad, que les obliga a formarse ante todo con el fin de dominar la naturaleza. La mediación conceptual se ve desde su interior como la esfera más importante, sin la que es imposible de conocer; pero esta apariencia no debe ser confundida con la verdad.

Outro tema fundamental apresentado naquela mesma obra é o da ontologia, singularmente mecanizada, a nosso ver, pelo mundo administrado (ainda expressão adorniana).

Habermas - discípulo de Adorno, embora discordante - expôs sua clássica teoria do agir comunicativo, assim explicitada por González de Gómez (2009, p. 197):

O agir comunicativo é uma forma de interação social na qual o plano de ação de vários agentes são coordenados mediante o intercâmbio de atos comunicativos - por intermédio do uso da linguagem verbalizada ou de expressões extraverbais correspondentes - orientados à obtenção do entendimento.

Para Habermas (2002, p. 13):

[...] qualquer pessoa que aja segundo uma atitutde comunicativa deve, ao efectuar qualquer tipo de acto de fala, apresentar pretensões de validade universal e supor que estas possam ser defendidas (einlösen). Se pretender participar num processo através do qual se procura chegar a um entendimento, não poderá evitar apresentar as seguintes (e, no fundo, precisamente as seguintes) pretensões de validade: pretenderá estar:

a) a enunciar de uma forma inteligível;

b) a dar (ao ouvinte) algo que este compreenderá;

c) a fazer-se a si próprio, desta forma, entender;

d) a atingir o seu objectivo de compreensão junto a outrem.

Rüdiger (2004, p. 98), com base no texto original (tradução espanhola), explica tais pretensões:

1. pretensão de compreensibilidade da mensagem: ninguém realmente entra em comunicação com outros se não tiver a pretensão de se fazer compreender ou ser compreendido.

2. pretensão de veracidade da mensagem: nós nos comunicamos pressupondo que, quando falamos sobre o mundo, estamos falando a verdade - sem esta pretensão não há verdadeira comunicação.

3. pretensão de correção valorativa da mensagem: nós nos comunicamos pressupondo que, quando falamos sobre os seres humanos, estamos falando de modo normativamente correto para as pessoas que nos ouvem com atitude idêntica, pois sem isso não pode haver comunicação.

4. pretensão de autenticidade subjetiva da mensagem: ninguém entra em comunicação com os outros se não supõe a sinceridade dos proferimentos do falante e da escuta do ouvinte, principalmente quando a mensagem se refere aos estados subjetivos dos participantes.

InCID: R. Ci. Inf. e Doc., Ribeirão Preto, v. 1, n.1, p. 125-137, 2010. 
Ao refletir sobre o tema, observa-se que todas as pretensões de validade encontram-se no trabalho bibliotecário, especialmente no que tange à catalogação. Há implícitas no registro bibliográfico as pretensões de veracidade, de correção valorativa, de autenticidade subjetiva. Almeja-se a plena compreensão do registro bibliográfico - nossa ação comunicativa - por parte dos usuários, em seus diversos momentos.

\section{Considerações finais}

Explica-se a afirmativa. A catalogação estabelece, por meio de sinais diversos, que o conteúdo do registro é verdadeiro (pretensão de veracidade); assinala por meio de colchetes ou pontos de interrogação as dificuldades na confirmação ou dúvidas sobre as informações; indica em notas diversos aspectos da obra, desde seus possíveis criadores ou responsáveis, a suas fontes de pesquisa, relações com outras obras e características de conteúdo. Estabelece como base a correção valorativa, na medida em que usa normas linguísticas corretas, assim como padrões e sinais catalográficos consistentes e universalmente acordados nas instâncias documentais, dentro de princípios éticos, respeitando valores diversificados de um mesmo grupo ou sociedade. Parte da autenticidade subjetiva da mensagem, porque um catalogador não pode mentir em seu registro bibliográfico, transcrever informações errôneas, inventar o que não sabe. Subjetivamente, precisa estar imbuído do princípio de veracidade em suas ações. Por fim, pode e deve adequar os padrões catalográficos normativos à compreensão de seus usuários. E como se justifica tal afirmação?

A adoção de normas permite: o intercâmbio da mensagem catalográfica entre instituições documentais no mundo, o que amplia as alternativas de escolha pelos usuários e auxilia outros profissionais; consistência sintática e semântica do registro bibliográfico, o que facilita o reconhecimento dos sinais e sua compreensão, pelo uso de linguagem comum. Porém, existe um fator determinante, em geral ignorado: a necessidade de uso de certo tipo de informação no registro depende da necessidade do usuário. O padrão consiste em: a partir do momento em que se elege uma informação, esta, obrigatoriamente, se deve transcrever de modo padronizado pela "gramática" da linguagem catalográfica.

Os exemplos apresentados sobre a CDD e as AACR demonstram que todos os profissionais de algum modo vinculados às informações bibliográficas necessitam conhecer 
os instrumentos catalográficos universais, compreender e interpretar suas instruções normativas (regras) e utilizá-los adequadamente. O uso equivocado de padrões (ausência de correção valorativa) leva ao oposto do que se pretende, isto é, à incompreensão; no entanto, esta incongruência não se pode tornar argumento para o desapreço acerca das ferramentas biblioteconômicas.

A máxima popular a teoria não se aplica à prática apenas demonstra o uso incorreto da teoria na prática, ou a inadequação da teoria àquela prática; ambas precisam ser revistas, não ignoradas. A análise reflexiva sobre a prática e a teoria é o que permite a evolução da área, assim como sua adequação à sociedade. Ou, segundo Adorno (1992, p. 90-91): “a relação da teoria e prática é, após seu mútuo afastamento, uma relação de salto qualitativo, não de transição e, de maneira alguma, de subordinação; ambas mantêm entre si relação de polaridade".

Este trabalho não se deteve nas necessárias análises dos textos citados e citou apenas alguns dos autores que merecem destaque nesta busca de teoria aplicada à prática; somente propôs-se a levantar alguns tópicos, despertar questionamentos e mostrar que há vários caminhos possíveis. Pensar a representação bibliográfica como ação comunicativa e vislumbrar outros olhares sobre nossas práticas talvez nos levem à significativa comunicação com os diferentes sujeitos da documentação.

\section{Referências}

ADORNO, Theodor W. Anotações sobre teoria e prática. In: . Quatro textos clássicos. Org. e trad. de Newton Ramos-de-Oliveira. 1992. Material não publicado destinado à circulação interna, UNESP/Araraquara e UFSCar.

Dialéctica negativa. Madrid: Taurus, 1975.

ADORNO, Theodor W.; HORKHEIMER, Max. Dialética do esclarecimento: fragamentos filosóficos. Rio de Janeiro: J. Zahar, 1985.

BIBLIOTECA NACIONAL (BRASIL). Documento da Biblioteca Nacional: Grupo de Trabalho sobre Processos Técnicos: 1983 e 1984. In: MEY, Eliane S. A. Não brigue com a catalogação! Brasília: Briquet de Lemos, 2003. p. 169-180.

CHAGAS, Valnir. Educação brasileira: o ensino de $1^{\circ}$ e $2^{\circ}$ graus. São Paulo: Saraiva, 1982. CÓDIGO de catalogação anglo-americano. 2. ed., rev. 2002. São Paulo: FEBAB, 2004. 
DECLARAÇÃO de princípios internacionais de catalogação. Trad. de Lídia Alvarenga e Márcia Milton Vianna. IFLA, 2009. Disponível em: < www.ifla.org/files/cataloguing/icp/icp_2009-pt.pdf>. Acesso em: 4 jul. 2010.

DECLARACIÓN de principios adopatados por la Conferencia Internacional sobre Principios de Catalogación París, octubre de 1961. Traducción: Elena Escolano Rodríguez. In: REUNIÓN IFLA DE EXPERTOS SOBRE UN CÓDIGO INTERNACIONAL DE CATALOGACIÓN, 2., 2004, Buenos Aires. Disponível em: < www.loc.gov/loc/ifla/imeicc/papers-sp.html>. Acesso em: 18 out. 2006.

DEWEY decimal classification and relative index. 22. ed. Dublin: OCLC, 2003. 4 v.

GONZÁLEZ DE GÓMEZ, Maria Nélida. A informação no pensamento contemporâneo: aproximações à teoria do agir comunicativo de Habermas. In: BRAGA, Gilda Maria; PINHEIRO, Lena Vania Ribeiro (Orgs.). Desafios do impresso ao digital: questões contemporâneas de informação e conhecimento. Brasília: Unesco, IBICT, 2009. p. 177-204.

HABERMAS, Jürgen. O que é a pragmática universal? In: Racionalidade e comunicação. Lisboa: Edições 70, 2002. p. 9-102.

IFLA. Cataloguing Section. International Standard Bibliographic Description (ISBD): preliminary consolidated edition. München: K.G. Saur, 2007. Disponível em:

$<$ http://www.ifla.org/publications/international-standard-bibliographic-description $>$. Acesso em: 4 jul. 2010.

Study Group on the Functional Requirements for Bibliographic Records. Functional Requirements for Bibliographic Records. München: K.G. Saur, 1998. Disponível em: $<$ http://www.ifla.org/en/publications/functional-requirements-for-bibliographic-records>. Acesso em: 4 jul. 2010.

MATTELART, Armand; MATTELART, Michèle. História das teorias da comunicação. 6. ed. São Paulo: Loyola, 2003.

MOSTAFA, Solange Puntel. Epistemologia da biblioteconomia. 1985. Tese (Doutorado) Pontifícia Universidade Católica, São Paulo, 1985.

RDA: resource description and access: full draft of RDA. JSC/RDA, 2009 [last update]. Disponível em: <http://www.rda-jsc.org/rdafulldraft.html>. Acesso em: 4 jul. 2010.

RÜDIGER, Francisco. Introdução à teoria da comunicação. 2. ed. São Paulo: EDICON, 2004.

Nota: As autoras, em algumas partes, citaram argumentos encontrados em outras obras próprias:

MEY, Eliane Serrão Alves. Acesso aos registros sonoros: elementos necessários à representação bibliográfica de discos e fitas. 1999. Tese (Doutorado) - Escola de Comunicação e Artes, Universidade de São Paulo, São Paulo, 1999.

MEY, Eliane Serrão Alves; SILVEIRA, Naira Christofoletti. Catalogação no plural. Brasília: Briquet de Lemos, 2009. 